\title{
Effects of L-amino Acids on Human Peripheral Neutrophil Granulocyte Activation
}

\author{
Sándor Sipka ${ }^{1, *}$, Tamás Keresztes ${ }^{2}$, Ildikó Kovács ${ }^{1}$, Sándor Sipka $\mathrm{Jr}^{2}$, Sándor Baráth ${ }^{1}$, \\ Gyula Szegedi $^{1+}$, Margit Zeher ${ }^{1}$ and Geza Bruckner ${ }^{3}$ \\ ${ }^{I}$ Division of Clinical Immunology, Department of Internal Medicine, University of Debrecen, Hungary \\ ${ }^{2}$ Department of Cardiology, University of Debrecen, Hungary \\ ${ }^{3}$ Division of Clinical Nutrition, University of Kentucky, KY, USA
}

\begin{abstract}
Objective: The objective was to investigate the early (20 minutes) effects of $21 \mathrm{~L}$-amino acids on the activation of human neutrophils and to determine in healthy individuals the effects of a meal on the 1) number and relative luminescence unit (RLU) of peripheral neutrophils, 2) serum glutamate and glucose levels and 3) mTOR signaling network.

Methods: The RLU of neutrophils stimulated by $\mathrm{Ca}^{2+}$ ionophor (CaI) and phorbol myristate acetate (PMA) following amino acid supplementation $\left(3 \times 10^{-4} \mathrm{M}\right)$ or after consuming a meal was determined. L-glutamate was measured by HPLC.

Results: All amino acids resulted in significant inhibitions of neutrophil RLU, except for arginine, which stimulated neutrophils. The ratios of amino acid induced inhibition were significantly higher in the cells stimulated by PMA than by $\mathrm{CaI}$. The consumption of a meal resulted in a significant serum glutamate elevation compared to baseline (2.3 versus $\left.0.9 \times 10^{-4} \mathrm{M}\right) 90$ minutes after ingestion of the meal. It was independent of the body mass index and returned near fasting levels after 150 minutes. The number of neutrophils was significantly elevated 90 minutes after the meal but the PMA induced RLU was significantly decreased.

Conclusion: Our ex vivo and in vivo results suggest that the L-amino acids, independent of their metabolic significance, may continuosly and quickly modify the activity of human peripheral neutrophils, and also the outcome of various immunologic reactions. The activation of the mTORC1 complex likely involves a transient impairment in the function of mTORC2 complex in these processes.
\end{abstract}

Keywords: L-amino acids, L-glutamate, mTOR, neutrophils, RLU.

\section{INTRODUCTION}

Plasma free amino acid concentrations have been measured for various purposes, such as to evaluate the individual's protein nutritional status, to determine amino acid requirements and circadian variations and to gain an understaning of the various metabolic aspects of amino acids [1]. Other than being components of proteins, some amino acids have individual biological or biochemical effects. Leucine [2], arginine [3], glutamine [4], and glutamate [5] have been extensively studied as signaling agents. In addition to its important role as a neurotransmitter, glutamate signaling has been described in peripherial tissues, e.g. in bone, pancreas, skin [6]. Furthermore, ionotropic glutamate receptors have been characterized in human lymphocytes [7].

\footnotetext{
*Address correspondence to this author at the Division of Clinical Immunology, Department of Internal Medicine, University of Debrecen, 4032 Debrecen, Hungary; Tel/Fax: 3652255-218;

E-mail: sipka@iiibel.dote.hu

${ }^{+}$This author has passed away two months ago but he was a member of the team in the Division of Clinical Immunology.
}

Although there are some studies reporting on the effects of some amino acids on imunne modulation, there are no comprehensiuve studies. Therefore the current study investigated the effects of 21 individual amino acids on neutrophil activation. The effects of eating a simple meal on serum glutamate and glucose concentrations in healthy subjects, along with parallel measurements of the number and RLU, namely, chemiluminescence (CL) of peripheral neutrophil granulocytes, were determined. Furthermore, we measured and compared the effects of $3 \times 10^{-4} \mathrm{M}$ of 21 amino acids, 20 minutes into the reaction, on the RLU of peripheral neutrophil granulocytes, stimulated and not stimulated by $\mathrm{CaI}$ and PMA ex vivo, in relation to the mTOR (mechanistic target of rapamycin) signaling network; thereby testing the dose dependent effect of rapamycin (R). Aminoacids have been shown to not only activate the mTOR1 complex but are also required for activation by other stimuli [8]. 


\section{SUBJECTS, MATERIALS AND METHODS}

\section{Donors}

A total of 34 healthy individuals (23 women, 18-51 years of age and 11 men, 17-60 years of age) free from disease and not consuming drugs or medications were included in the study. Fifteen of them took part in both the in vivo (two times) and ex vivo studies (five times). The protocol was approved by the Institutional Review Board, and informed consent was obtained from all participants. The body mass indexes (BMI) were determined from height and weight.

\section{Breakfast}

After a 12 hour fast, the volunteers of the study were asked to eat $28 \mathrm{~g}$ of commercial cheese and $88 \mathrm{~g}$ of salt rolls at $8 \mathrm{am}$. The meal contained $16.8 \mathrm{~g}$ of protein, $59.4 \mathrm{~g}$ of carbohydrate and $10.5 \mathrm{~g}$ of fat. Water was consumed ad libitum.

\section{Blood testing}

Prior to consumption of breakfast and 90 minutes following breakfast, serum samples were prepared from each subject for testing of glucose and glutamate levels. Additionally, in 3 subjects the levels of glutamate were measured at 150 and 210 minutes after the meal.

\section{Materials}

Calcium ionophore (ionomycin) (CaI), phorbol 12myristate 13-acetate (PMA), rapamycin (R), luminol (5-amino-2, 3-dihydro-1, 4-phtalazinedione), and the 21 L-amino acids were purchased from Sigma-Aldrich, St. Louis, MO, USA.

\section{Meaurement of Glucose and L-glutamate}

The measurement of glucose was carried out by an automated hexokinase/glucose 6 phosphate method (Roche) and glutamate was determined by RP- HPLC. The analytical methods for the determination of free amino acids in serum are well known [9]. The deproteinization of samples by methanol was followed by derivatization with phenylisothiocyanate (PIRC) to form stable phenylthiocarbamylamino acid (PTCA) derivatives. The derivatives were separated by RP-HPLC and the glutamate peaks were evaluated using a D-6000 interface and a D-7000 system-maneger softwere (Merck-Hitachi, Burladingen, Germany).

\section{Measurement of RLU of Human Neutrophils Stimulated by CaI or PMA ex vivo}

The erythtocyte-neutrophil rich pellets of Ficoll-Uromiro gradient centrifugation were sedimented by dextrane at $37{ }^{\circ} \mathrm{C}$ for 45 minutes. The erythrocytes contaminating the suspensions of neutrophils were lysed by hypotonic $\mathrm{NH}_{4} \mathrm{Cl}$. The final suspensions of neutrophils were adjusted to $10^{7} / \mathrm{ml}$ in (methyl-red free, colourless) Hank's culture medium.

The purity and viability of cells were higher than $95 \%$. Neutrophils $\left(5 \times 10^{6} / \mathrm{ml}\right)$ were stimulated by $10^{-7} \mathrm{M}$ of calcium ionophore $(\mathrm{CaI})$ or $10^{-9} \mathrm{M}$ of PMA in the presence of $10^{-7} \mathrm{M}$ of luminol. The RLU of cells was measured by a luminometer (Bertold, Germany) and its value was expressed in relative luminescence unit (RLU). The RLU values measured at the 20th minute time periods were compared in the stimulated and not stimulated cell suspensions in the absence or presence of $3 \times 10^{-4} \mathrm{M}$ of each amino acid, dissolved in Hank's solution.

For a stock solution, $\mathrm{R}$ was dissolved in ethanol from which further dilutions were made using Hank's solution. The final concentrations of $\mathrm{R}$ were as follows: $10^{-8} \mathrm{M}(\mathrm{R} 1)$,

$10^{-7} \mathrm{M}(\mathrm{R} 2), 10^{-6} \mathrm{M}$ (R3).

\section{Testing of the Viability of Neutrophils}

The viability of neutrophils was tested after 20 minutes using the Trypan-blue exclusion test and evaluated microscopically (never falling below 90\%) or the measurement of lactate dehydrogenase release by an automated laboratory equipment (Roche) (never exceeding the value of $10 \mathrm{U} / 1$ ).

\section{Statistical Analysis}

The results represent the mean $\pm \mathrm{SD}$ values of at least three repeated experiments. Normal distribution of data was tested using the Kolmogorov-Smirnov test. Kruskal-Wallis test was used to compare the groups of data in the in vivo experiments. Data of ex vivo investigations were analysed for statistically significant differences using paired $t$ and Pearson correlation tests. The difference between the various groups was tested by the analysis of variance (ANOVA) with Tukey post hoc test. The correlation coefficients were calculated using the Spearman rank test. The statistical analysis was performed by the SPSS 15.0 statistical software (SPSS Inc. Chicago, IL). The statistical significance was defined as $\mathrm{p} \leq 0.05$.

\section{RESULTS}

\section{Changes in the Serum Levels of L-glutamate and Glucose} Measured Before and After Breakfast

Thirty one healthy subjects were tested in vivo after a 12 hours fast and 90 minutes after eating breakfast for changes in serum glutamate and glucose concentrations. The levels of glutamate increased significantly from baseline after the meal $\left(0.94 \pm 0.41\right.$ versus $\left.2.28 \pm 1.76 \times 10^{-4} \mathrm{M} . \mathrm{p}<0.001\right)$, as well as the serum glucose concentration $4.36 \pm 0.54$ to 5.06 $\pm 0.99 \times 10^{-3} \mathrm{M}(\mathrm{p}<0.001)$.

The increase in the serum glutamate levels was independent of the BMI (correlation coefficient $=0.20$, n.s.); whereas the glucose elevation was dependent on BMI (correlation coefficient $=0.53, \mathrm{p}<0.003$ ).

In three healthy donors, the increased serum glutamate levels returned to near fasting levels 150 minutes after the breakfast. (These data are not presented.)

Changes in the Number and RLU of Peripheral Neutrophils, 90 Minutes after Breakfast in Healthy Subjects

In 12 healthy subjects, the number of circulating neutrophils was significantly elevated 90 minutes after breakfast $(3.8 \pm 1.7$ versus $4.40 \pm 2.1 \mathrm{G} / \mathrm{L} \mathrm{p}<0.05)$ tested in 
Table 1. The ex vivo effects of various L-amino acids on the RLU of human neutrophils stimulated or not stimulated by CaI and PMA.

\begin{tabular}{|c|c|c|c|}
\hline $\begin{array}{c}\text { Amino acids with non polar, aliphatic } \\
\text { groups }\end{array}$ & $\begin{array}{c}\text { Cells+Amino acids RLU \% } \\
\operatorname{means}(n=3)\end{array}$ & $\begin{array}{l}\text { Cells+Amino acids +CaI } \\
\text { RLU \% means }(n=3)\end{array}$ & $\begin{array}{l}\text { Cells+Amino acids +PMA } \\
\text { RLU \% means }(n=3)\end{array}$ \\
\hline Glycine & $55^{*}$ & $46^{*}$ & $32 * *$ \\
\hline Alanine & 91 & 95 & 66 \\
\hline Valine & 82 & 94 & 67 \\
\hline Leucine & 92 & 103 & $57^{*}$ \\
\hline Isoleucine & 87 & 104 & 67 \\
\hline Proline & $57^{*}$ & $57^{*}$ & $34 * *$ \\
\hline Methionine & $49^{*}$ & $48^{*}$ & $14 * *$ \\
\hline Amino acids with aromatic groups & $\begin{array}{l}\text { Cells+Amino acids } \\
\text { RLU \% means }(n=3)\end{array}$ & $\begin{array}{l}\text { Cells+Aminio acids } \\
\quad+\text { CaI } \\
\text { RLU \% means }(n=3)\end{array}$ & $\begin{array}{l}\text { Cells+Amino acids +PMA } \\
\text { RLU \% means }(n=3)\end{array}$ \\
\hline Thyrosine & $40^{*}$ & $52 *$ & $6 * * *$ \\
\hline Tryptophan & 110 & 82 & $14 * * *$ \\
\hline Phenylalanine & $51^{*}$ & $44^{*}$ & $25^{* *}$ \\
\hline Aminoacids with uncharged groups & $\begin{array}{l}\text { Cells+Amino acids } \\
\text { RLU \% means }(n=3)\end{array}$ & $\begin{array}{l}\text { Cells+Amino acids } \\
\quad+\text { CaI } \\
\text { RLU \% means }(n=3)\end{array}$ & $\begin{array}{c}\text { Cells+Amino acids } \\
\text { +PMA } \\
\text { RLU \% means }(n=3)\end{array}$ \\
\hline Serine & $44^{*}$ & $38^{* *}$ & $15 * * *$ \\
\hline Threonine & $47^{*}$ & $43^{*}$ & $16^{* * *}$ \\
\hline Cysteine & $36 * *$ & $37 * *$ & $2 * * *$ \\
\hline Cystine & 69 & 75 & $35 * *$ \\
\hline Asparagine & $47 *$ & $49^{*}$ & $15 * * *$ \\
\hline Glutamine & $46^{*}$ & $42 *$ & $20 * *$ \\
\hline $\begin{array}{c}\text { Aminoacids with negatively charged } \\
\text { groups }\end{array}$ & $\begin{array}{l}\text { Cells+Amino acids } \\
\text { RLU \% means }\end{array}$ & $\begin{array}{c}\text { Cells+Amino acids } \\
\text { +CaI } \\
\text { RLU \% means }\end{array}$ & $\begin{array}{c}\text { Cells+Amino acids } \\
\text { + PMA } \\
\text { RLU \% means }\end{array}$ \\
\hline Glutamate & $48^{*}(\mathrm{n}=15)$ & $42 *(n=15)$ & $21 * *(n=15)$ \\
\hline Asparagine acid & $47 *(n=3)$ & $49 *(n=3)$ & $15^{* * *}(\mathrm{n}=3)$ \\
\hline $\begin{array}{c}\text { Aminoacids with positively charged } \\
\text { groups }\end{array}$ & $\begin{array}{l}\text { Cells+Amino acids } \\
\text { RLU \% means }(n=3)\end{array}$ & $\begin{array}{c}\text { Cells+Amino acids } \\
\text { +CaI } \\
\text { RLU \% means }(n=3)\end{array}$ & $\begin{array}{c}\text { Cells+Amino acids } \\
\text { + PMA } \\
\text { RLU \% means }(n=3)\end{array}$ \\
\hline Lysine & $39 * *$ & $48^{*}$ & $20 * *$ \\
\hline Histidine & $37 * *$ & $56^{*}$ & $22 * *$ \\
\hline$M e a n \pm S D(n=20)$ & $58.70 \pm 21.80$ & $60.20 \pm 22.82$ & $28.15 \pm 20.33^{* * *}$ \\
\hline Arginine & $244(N O) * *$ & $191(N O) * *$ & $93(N O)$ \\
\hline
\end{tabular}

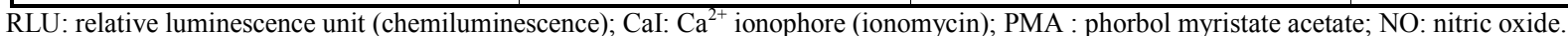
$* \mathrm{p}<0.05 ; * * \mathrm{p}<0.01 ; * * \mathrm{p}<0.001$.

vivo. The RLU of the circulating, not stimulated neutrophils (standardized on the same cell count) was also significantly increased $(273 \pm 129$ versus $342 \pm 46$ RLU, $p<0.05)$, whereas the PMA induced RLU of these cells was significantly decreased $(2200 \pm 751$ versus $1681+519$ RLU, $\mathrm{p}<0.05)$ measured ex vivo in whole heparinized blood. 
The ex vivo Effects of Various L-amino Acids on the RLU of Human Neutrophils Stimulated or Not Stimulated by CaI and PMA

The RLU data of purified neutrophils, stimulated or not stimulated for 20 minutes by $\mathrm{CaI}$ and PMA ex vivo in the presence of $21 \mathrm{~L}$-amino acids, $\left(3 \times 10^{-4} \mathrm{M}\right)$ are depicted in Table 1. In the Table, a RLU value measured in the presence of a certain amino acid was expressed as a percent of the RLU found in the absence of the amino acid (RLU $=100 \%$ ); only the statistical means of the RLU data (derived from at least three measurements) for each amino acid and the levels of significance are depicted. The following conclusions can be drawn: a.) the effects of some amino acids (alanine, valine, leucine, isoleucine, tryptophan) were not significant on the $\mathrm{CaI}$ stimulated and non-stimulated cells compared to other amino acids resulting in significant inhibitions in all experimental systems (except for arginine); b.) the CL of neutrophils was significantly lower $(28.15 \pm 20.33$ versus $60.20 \pm 22.82 ; \mathrm{RLU}, \mathrm{p}<0.001)$ in the cells stimulated by PMA than in those stimulated by $\mathrm{CaI}$ in the presence of 20 amino acids even at a much lower concentration of PMA $\left(10^{-9} \mathrm{M}\right)$ than that of $\mathrm{CaI}\left(2 \times 10^{-7} \mathrm{M}\right) ;$ c.) arginine alone increased significantly the RLU in the non-stimulated cells and in those stimulated by $\mathrm{CaI}$. These data are shown in Table $\mathbf{1}$.

The ex vivo Effects of Rapamycin on the RLU of Human Neutrophils Stimulated by CaI and PMA in the Presence and Abscence of L-glutamate

Table 2. shows the changes in RLU of neutrophils, with or without glutamate, stimulated by $\mathrm{CaI}$ and by PMA in the absence or presence of three different doses of rapamycin (R), a blocking agent of mammalian mTORC1 complex 1 [8]. The final concentrations were as follows: R1:10 ${ }^{-6}$, R2: $10^{-7}$, R3: $10^{-8} \mathrm{M}$, L-glutamate: $3 \times 10^{-4} \mathrm{M}$. The three concentrations of $\mathrm{R}$ decreased the RLU of neutrophils stimulated by $\mathrm{CaI}$. This inhibition, however, was only significant at $10^{-7} \mathrm{M}$ (RLU: $59 \%$ ). In the non-stimulated cells, $\mathrm{R}$ caused a minimal non significant elevation. The inhibitions caused by the combination of $\mathrm{R}$ and glutamate were additive but not significant.
Testing the changes in RLU of neutrophils stimulated by PMA in the presence and abscence of three different doses of $\mathrm{R}$ and with or without L-glutamate, $\mathrm{R}$ resulted in a weak, non significant, non dose dependent increase in the RLU of both stimulated and not stimulated neutrophils. In addition, the presence of $\mathrm{R}$ did not alter the inhibition caused by glutamate in the PMA stimulated cells. Whereas, R slightly increased the RLU of PMA free neutrophils even in the presence of glutamate.

\section{DISCUSSION}

Knox van Dyke summarized the main processes of neutrophil RLU as based upon the activation of NADPH oxidase, producing superoxide anions, followed by the participation of dismutases and myeloperoxidase [10]. In both CaI or PMA induced RLU reactions of neutrophils, the mobilization of intracellular $\mathrm{Ca}^{2+}$, the production of diacyl glycerol (DAG) by phopholipase C, furthermore, the production of arachidonic acid by phospholipase $\mathrm{A}_{2}$ enzymes triggering $\mathrm{PKC}$ enzymes have been shown to play crucial roles [11-14]. NADPH oxidase can be activated by two types of protein kinase $\mathrm{C}$ isoenzymes 1.) requiring both $\mathrm{Ca}^{2+}$ and DAG, 2.) requiring only DAG [12-14].

L-glutamate is the most widely investigated amino acid as a signaling molecule [6], having receptors on human lymphocytes [7]. The current in vivo study showed that glutamate concentration increased significantly 90 minutes after breakfast, it reached the values of $2.28+1.76 \times 10^{-4} \mathrm{M}$ but it returned near the fasting value at 150 minutes. For this reason a nearly similar concentration of $3.0 \times 10^{-4} \mathrm{M}$ was used for the other amino acids in the ex vivo studies. Similar in vivo investigations were carried out also in Taiwan in 1999 [1]. In this study, the circadian variations in the plasma levels of glutamate, glutamine and alanine were measured in 10 healthy men fed ordinary Taiwanese meals (included breakfast, lunch and dinner). The mean age of subjects was 24 years, the mean body weight was $63.8 \mathrm{~kg}$, and the mean height was $170 \mathrm{~cm}$. In our 34 heathy donors, the number of men was 11 , the number of women was 23 , with a mean age of 40.9 years, mean weight of $73.7 \mathrm{~kg}$ and mean height of

Table 2. The ex vivo effects of rapamycin on the RLU of human neutrophils stimulated by CaI and PMA in the presence and abscence of L-glutamate.

\begin{tabular}{|c|c|c|c|c|c|c|c|c|}
\hline Samples & Cells & Cells +CaI & Cells+R1 & Cells +R1 + CaI & Cells+R2 & Cells $+\mathbf{R 2}+\mathrm{CaI}$ & Cells+R3 & Cells $+\mathrm{R3}+\mathrm{CaI}$ \\
\hline $\begin{array}{l}\text { Cells without glutamate RLU\% } \\
\text { means }(n=3)\end{array}$ & 100 & 100 & 105 & 78 & 110 & $59 *$ & 115 & 76 \\
\hline $\begin{array}{l}\text { Cells with glutamate } \mathrm{RLU} \% \text { means } \\
\qquad(\mathrm{n}=3)\end{array}$ & $48^{*}$ & $42 *$ & $39 * *$ & $37 * *$ & $28 * *$ & $35 * *$ & $49^{*}$ & $31 * *$ \\
\hline Samples & Cells & Cells +PMA & Cells+R1 & $\begin{array}{c}\text { Cells +R1 } \\
+ \text { PMA }\end{array}$ & Cells + R2 & $\begin{array}{c}\text { Cells +R2 } \\
\text { +PMA }\end{array}$ & Cells + R3 & $\begin{array}{c}\text { Cells +R3 } \\
+ \text { PMA }\end{array}$ \\
\hline $\begin{array}{l}\text { Cells without glutamate RLU\% } \\
\text { means }(n=3)\end{array}$ & 100 & 100 & 105 & 118 & 110 & 115 & 115 & 105 \\
\hline $\begin{array}{l}\text { Cells with glutamate RLU\% means } \\
\qquad(\mathrm{n}=3)\end{array}$ & $48^{*}$ & $21^{* *}$ & $35^{* *}$ & $20^{* *}$ & $53^{*}$ & $23 * *$ & $68^{*}$ & $19 * * *$ \\
\hline
\end{tabular}

RLU: relative luminescence unit (chemiluminescence); $\mathrm{CaI}: \mathrm{Ca}^{2+}$ ionophore (ionomycin); PMA: phorbol myristate acetate; R: rapamycin; *RLU\% means (4x);

$* * \mathrm{p}<0.01 ; * * * \mathrm{p}<0.001$ 
$168.9 \mathrm{~cm}$. However, there were stiking differences in the levels of glutamate measured in the two groups. In the Taiwanese group, both the fasting and the maximum concentrations of glutamate after breakfast were approximately half of the concentrations found in the present Hungarian cohort while consuming similar amounts of protein. These differences may be due to different mean ages (24 versus 40.9 years), different distributions of the genders and other components of the diets [15].

The testing of the neutrophils in the healthy donors, 90 minutes after ingesting a meal resulted in the following: 1.) The number of neutrophils and their RLU increased significantly in the blood. We speculate that the elevation in the number of circulating neutrophils is the result of cortisol, produced and released after the meal and thereby stimulating vessel wall adhered neutrophils to enter the circulation $[16$, 17]. The increased RLU observed might be due to the increase in serum glucose levels providing for an oxidative burst by the neutrophils [18], The activation of neutrophils by PMA in the blood, 90 minutes after the meal was significantly reduced compared to the pre-meal baseline. These findings suggest that following a high protein meal, the appearance of a transient immune-compromised state can occur. Of concern may be the impact of high protein intakes in body builders or other conditions where high protein intakes are recommended.

In order to test whether the decreased RLU of neutrophils could be related to the increased serum level of glutamate or that of other amino acids, the effects of all $21 \mathrm{~L}$-aminoacids on the RLU of neutrophils stimulated and non stimulated by $\mathrm{Ca}^{2+}$ ionophore (CaI) and PMA, were tested ex vivo. Most of the amino acids used at this concentration caused significant decreases in the RLU of stimulated and non stimulated cells at the 20 minute measurement. The RLU values were significantly lower in the cells stimulated by PMA than that by $\mathrm{CaI}$ evaluated as means of 20 amino acids, although, the inhibitions caused by alanine, valine, leucine, isoleucine and tryptophan were minimal in the $\mathrm{CaI}$ stimulated and non stimulated cells. On the other hand, arginine induced a rather intensive RLU in the non stimulated and $\mathrm{CaI}$ stimulated cells, likely through the production of NO reacting with luminol. For the structural classification of aminoacids the table from the handbook "Lehninger Principles of Biochemistry" was used [19].

The mechanistic target of rapamycin on signaling pathways, that sense and integrate a variety of environmental cues to regulate organismal growth and homeostasis, is via the mTOR pathway. mTOR is an atypical serine/threonine proteine kinase that belongs to the phosphoinositide 3 kinase (PI3K) related kinase family and interacts with several proteins to form two distinct complexes named, mTOR complex1 (mTORC1) and 2 (mTORC2). mTORC1 regulates cell growth and cell cycle progression; amino acids activate, rapamycin inhibits its activity. mTORC 2 is related to cytoskeletal organization, cells survival and to PKC $\alpha$. In the linkages between mTORC1 and mTORC2 complexes the various protein kinase $(\mathrm{A}, \mathrm{G}, \mathrm{C})$, phospholipase $\left(\mathrm{A}_{2}\right.$ and $\left.\mathrm{D}\right)$ isoenzymes and the actual intracellular $\mathrm{Ca}^{2+}$ levels play determinate roles [14, 20-23].
The involvement of mTOR receptors in the reactions tested in our experiments may occur via the following mechanisms: 1) by changing the available intracellular $\mathrm{Ca}^{2+}$ levels required for NADPH oxidase; 2) by the linkage of mTORC2 to the phosphorylation of PKC isoenzymes needed for the activation of NADPH oxidase [12, 22]. Amino acids can induce conformational changes of mTORC1 and can increase the intracellular level of $\mathrm{Ca}^{2+}$ enhancing its interaction with $\mathrm{Ca}^{2+} / \mathrm{CaM}$ (calcium/calmodulin dependent) kinase, causing a relative lack of calcium for other pathways [22]. Although amino acids might elevate the intracellular $\mathrm{Ca}^{2+}$ level during the activation of mTORC1, its consumption by $\mathrm{Ca} / \mathrm{CaM}$ kinase could result in a relative lack of available calcium for the activation of PKC $\alpha$ related to mTORC2 pathway, causing a weaker stimulation of NADPH oxidase. The activation of the mTORC1 complex involves a transient impairment in the function of mTORC2 complex in these processes. In the greater inhibition of neutrophil RLU (expressed in per cent and not in absolute RLU values) caused by the amino acids in the system stimulated by a much smaller $\left(10^{-9} \mathrm{M}\right)$ dose of PMA than in that where the cells were stimulated by a much higher dose $\left(10^{-7} \mathrm{M}\right)$ ionomycin, different pathways could play the major roles. Namely, PMA stimulated RLU of human neutrophils may represent a more sensitive and specific pathway related to the PKC isoenzymes in which any intracellular metabolic change can result in a greater alteration than in the pathway involving the $\mathrm{Ca}^{2+}$ dependent ion channels stimulated by $\mathrm{Ca}^{2+}$ ionophore. We chose the $20^{\text {th }}$ minute time period to be the standard time for comparision of the various test systems, because this was the time of peak RLU with PMA. In addition, any toxic effect of aminoacids tested ex vivo could be excluded still at this early time of treatment. The comparison of changes induced by the amino acids in the PMA and CaI stimulated neutrophils was in percent change from the untreated cells which represent 100 percent in each system.

Rapamycin, at $10^{-7} \mathrm{M}$ concentration inhibited significantly the RLU of neutrophils stimulated by $\mathrm{CaI}$, and showed some additive inhibitory effect along with glutamate. On the other hand, R was basicly ineffective on the RLU of PMA stimulated cells either in the presence or absence of glutamate, suggesting an opposite effect compared to the results of rapamycin-free systems. We suggest that these observations can be explained by the direct effects of $\mathrm{R}$ on calicium metabolism, on the preservation of $\mathrm{Ca}^{2+}$ homeostasis and prevention of $\mathrm{Ca}^{2+}$ overload via extrusion of calcium surplus $[22,23]$, and not only by its reaction with mTORC1.

It has to be stressed, however, that in the ex vivo amino acid experiments we tested only their early (20 minutes) effects and not their influence on the protein metabolism of these cells appearing later (after hours or days) [24]. We think that the differences in the early in vivo and ex vivo effects of the single amino acids can be related to the differences in their penetration times and concentrations across the cell membrane. For example, for cystine and glutamate special transporter molecules are expressed in the human peripheral neutrophils [25] (both amino acids caused really great inhibition), whereas other amino acids may 
require a longer time or other transporters to enter these cells [26].

Confirming our results, articles various inflammation modulating effects of L-glutamate [27] and L-arginine [28] were observed in vivo.

\section{CONCLUSION}

In conclusion, our in vivo and ex vivo experimental data suggest that the L-amino acids, independent of their metabolic significance, may continuosly and quickly modify the activity of human peripheral neutrophil granulocytes and also the outcome of various immunologic reactions [27, 28]. Both the mTORC1 and mTORC2 axises of mTOR signaling pathway can be involved in these processes, as the activation mTORC1 complex by the amino acids involves a transient impairment in the function of mTORC2 complex in these processes. $[20,29]$. These findings suggest that high protein diets may have adverse effects on immune modulation.

\section{ABBREVIATIONS}

$\begin{array}{lll}\mathrm{BMI} & = & \text { body mass index } \\ \mathrm{Ca} & = & \text { calcium } \\ \mathrm{CaI} & \mathrm{Ca}^{2+} \text { ionophore (ionomycin) } \\ \mathrm{CAM} & = & \text { calmodulin dependent } \\ \mathrm{CL} & = & \text { chemiluminescence } \\ \mathrm{DAG} & = & \text { diacyl glycerol } \\ \mathrm{G} / \mathrm{L} & = & \text { Giga/liter } \\ \mathrm{M} & = & \text { molar } \\ \mathrm{mTOR} & = & \text { mammalian target of rapamycin } \\ \mathrm{n} & = & \text { number of samples } \\ \mathrm{NADPH} & = & \text { nicotinamid adenine } \\ & & \text { phosphate } \\ \mathrm{NO} & = & \text { nitric oxide } \\ \mathrm{PKC} & = & \text { photein kinase C } \\ \mathrm{PMA} & = & \text { rapamycin } \\ \mathrm{R} & & \end{array}$

\section{CONFLICT OF INTEREST}

The authors declare that there is no conflict of interest that would prejudice the impartiality of this scientific work.

\section{ACKNOWLEDGEMENTS}

We thank for the excellent technical help from Marianna Széles, Anikó Karcza, Anikó Tormás and Csaba Kun MD, and for the healthy donors who voluntarily participated in this study.

\section{FUNDING}

This work was supported by the grant of Hungarian Research Fund (OTKA 71883).

\section{REFERENCES}

[1] Tsai PJ, Huang PC. Circadian variations in plasma and erythrocyte concentrations of glutamate, glutamine, and alanine in men on a diet without and with added monosodium glutamate. Metabolism 1999; 48: 1455-60.

[2] Ishizuka Y, Kakiya N, Nawa H, Takei N. Leucine induces phosphorylation and activation of p70S6K in cortical neurons via the system L amino acid transporter. J Neurochem 2008; 106: 934-42

[3] Schow EV, Freites JA, Cheng et al. Arginine in membranes: the connection between molecular dynamics stimulation and translocon mediated insertion experiments. J Membrane Biol 2011; 239: $35-48$.

[4] Uderzo C, Rebora P, Marrocco E, et al. Glutamin- enriched nutrition does not reduce mucosal morbodity or complications after stem-cell transplantation for childhood malignancies: a prospective randomized study. Transplantation 2011; 91: 1321-5.

[5] Abe K, Saito H. Possible linkage between glutamate transporter and mitogen-activated protein kinase cascade in cultured rat cortical astrocytes. J Neurochem 2001; 76: 217-23.

[6] Hinoi E, Takarada T, Ueshima T, Tsuchihashi Y, Yoneda Y. Glutamate signaling in peripheral tissues. Eur J Biochem 2004; 271: 1-13.

[7] Lombardi D, Dianzani C, Miglio G, Canonico PL, Fantozzi R Characterization of ionotropic glutamate receptors in human lymphocytes. Br J Pharmacol 2001; 133: 936-44.

[8] Kim J, Guan KL. Amino acid signaling in TOR activation. Annu Rev Biochem 2011; 80: 1001-3.

[9] Lavi E, Holcenberg JS. Sensitive analysis of asparagine and glutamine in physiological fluids and cells by precolumn derivatization with phenylisothiocyanate and reversed-phase highperformance liquid chromatography. J Chromatogr 1968; 377 : 155-63.

[10] Van Dyke K. Soluble and insoluble activators of neutrophils chemiluminescene. In: Van Dyke K, Castranova V. Eds. Cellular RLU. Florida: CRP Press Inc. 1987; vol. I. Chapter 13. pp. 161-72.

[11] Dedkova EN, Alovskaya AA, Gabdulhakova AG, Safronova VS, Zichenko VP. Priming effect of calcium ionophores on PMA induced respiratory burst in mouse peritoneal neutrophils. Biochemistry (Mosc) 1999; 64: 788-94.

[12] Fontayne A, Dang PM, Gougerot-Pocidalo MA, El-Benna J. Phosphorylation of p47phox sites by PKC alpha, beta II, delta, and zeta: effect on binding to p22phox and on NADPH oxidase activation. Biochemistry 2002; 41: 7743-50.

[13] Pandey D, Fulton DJ. Molecular regulation of NADPH oxidase 5 via the MAPK pathway. Am J Physiol Heart Circ Physiol 2011; 300: 1336-44.

[14] Sipka S. Adenosine inhibits the release of arachidonic acid in activated human peripheral mononuclear cells. A proposed model for physiologic and pathologicregulation in systemic lupus erythematosus. ScientificWorldJournal 2011; 11: 972-80.

[15] Tovar AR, Ascencio C, Torres N, Gomez E, Bourges H. Neutral and basic amino acid concentrations in plasma during the day in subjects fed with two model rural and two model urban Mexican diets. Am J Clin Nutr 1996; 63: 335-41.

[16] Boyum A, Ronsen O, Tennfjord VA, et al. RLU response of granulocytes from elite athlethes during recovery from one or two intense bouts of exercise. Eur J Appl Physiol 2002; 88: 20-8.

[17] Lefebvre PJ, Luyckx AS. The breakfast tolerance test: a return to physiology. Diabete Metab 1976; 2: 15-9.

[18] Freitas M, Porto G, Lima JL, Fernandes E. Optimization of experimental settings for the analysis of human neutrophils oxidativite burst ex vivo.Talanta 2009; 78: 1476-83.

[19] Nelson DL, Cox MM. Amino Acids, Peptides and Proteins. In: Nelson DL, Cox MM, Eds. Lehninger Principles of Biochemistry, New York W. H. Freemen and Company 2005; p:78.

[20] Laplante M, Sabatini DM. mTOR signaling in growth control and disease. Cell 2012; 149: 274-92. 
[21] Avruch J, Long X, Ortiz-Vega S, Rapley J, Papageorgiou A, Dai N. Amino acid regulation of TOR complex 1. Am J Physiol 2009; 296: E592 -602.

[22] Magnuson B, Ekim B, Fingar DC. Regulation and function of ribosomal protein $\mathrm{S} 6$ (S6K) within mTOR signallaing networks. Biochem J 2012; 441: 1-21.

[23] Razmara M, Heldin CH, Lennartsson J. Platelet-derived growth factor induced Akt phosphorylation requires $\mathrm{mTOR} /$ Rictor and phospholipase C- $\gamma 1$, whereas S6 phosphorylation depends on mTOR/Raptor and phospholipase D. Cell Commun Signal 2013; 11: 3-10.

[24] Gallinetti J, Harputlugil E, Mitchell JR. Amino acid sensing in dietary restriction mediated longevity: roles of signal transducing kinases GCN2 and TOR. Biochem J 2013; 449: 1-10.
[25] Sakakura Y, Sato H, Shiiya A, et al. Expression and function of cystine/glutamate transporter in neutrophils. J Leukoc Biol 2007; 81: 974-82.

[26] Verrey F, Closs El, Wagner CA, Palacin M, Endou H, Kanai Y. CAT and HATs: the SLC7 family of amino acid transporters. Pflügers Arch 2004; 447: 532-42.

[27] Talá A, Monaco C, Nagorska K, et al. Glutamate utilization promotes meningococcal survival in vivo through avoidance of the neutrophil burst. Mol Microbiol 2011; 81: 1330-42.

[28] Coburn LA, Gong X, Singh K, et al. L-arginin supplementation improves responses to injury and inflammation in dextran sulphate sodium colitis. PLoS One 2012; 7(3): e33546.

[29] Procaccini C, Galgani M, De Rosa V, Matarese G. Intracellular metabolic pathways control immune tolerance. Trends Immunol 2012; 33: 1-7.

(C) Sipka et al.; Licensee Bentham Open

This is an open access article licensed under the terms of the Creative Commons Attribution Non-Commercial License (http://creativecommons.org/licenses/by-nc/3.0/) which permits unrestricted, non-commercial use, distribution and reproduction in any medium, provided the work is properly cited. 